\title{
Un momento en la historia del español de Chile*
}

\author{
An Instant in the History of Chilean Spanish
}

\author{
Manuel Contreras \\ Universidad de Los Lagos, Departamento de Humanidades y Artes, Osorno, Chile. \\ e-mail: mcontrer@ulagos.cl
}

El presente artículo es una síntesis de la caracterización fonética que ha tenido el español de Chile desde sus orígenes (siglo XVI) hasta fines del período colonial (siglo XVIII). Se analiza un corpus documental tanto de autores peninsulares como criollos, donde se recorren los principales rasgos que caracterizan esta variedad dialectal. El artículo parte contextualizando el estudio, para luego centrarse en las características de la fonética de los peninsulares que llegan al 'Reino de Chile', pasando luego al habla de los criollos chilenos.

Palabras clave: español de Chile, período colonial, fonética histórica.

The present article is a synthesis of the phonetic characterization that has had the Chilean Spanish Language from its origins (XVI century) to the end of the colonial period (XVIII century). A documentary corpus of peninsular authors is analyzed as much as "criollos", where the main features that characterize this dialectal variety are shown. The article starts contextualizing the study, then it centers on the characteristics of peninsular phonetics of the population that arrived at the 'Kingdom of Chile', and finally it analyzes the speech of the Chilean "criollos".

Keywords: Chilean spanish language, colonial period, historical phonetics.

\section{INTRODUCCIÓN}

Este artículo se propone establecer una visión globalizadora de los procesos históricos de formación y desarrollo del español en Chile durante el período colonial -siglos XVI al XVIII- en sus aspectos fonéticos, los cuales aún no han recibido un tratamiento a fondo de sus características particularizadoras (cfr. Contreras 2000, 2004). Con este objeto se analizará una serie de rasgos lingüísticos que dan cuenta del ámbito fonético dentro del que se movían los autores de nuestros documentos.

No deja de ser un dato importante el que los resultados obtenidos por el análisis empírico nos permita cuestionar las etapas linguísticas que se han propuesto para el período hispanoamericano, como, por ejemplo, la de De Granda ${ }^{1}$ :

La primera de ellas, de ámbito hispanoamericano general y de sentido homólogo en su evolución y direccionalidad final, está centrada en el desarrollo de un proceso de koineización que, a partir de una situación inicial de heterogeneidad lingüística originada en la traslación a tierras americanas de las diferenciaciones diatópicas y diastráticas de la metrópoli, conduce progresivamente hacia un estadio final caracterizado por la cristalización de una modalidad lingüística común, obtenida por convergencia de las variantes de uso anteriormente existentes.

La segunda /.../ puede considerarse finalizada en líneas generales /.../ con la independencia de las diferentes naciones hispanoamericanas, /.../ manifiesta evoluciones claramente divergentes en su sentido y significación. Y en cuanto a la modalidad de cambio que, de entre ellas, debe ser apreciada como más relevante, la estandarizadora, no sólo no está presente en la totalidad de las áreas geográficas hispanoamericanas sino sólo en algunas de ellas sino que, además, la misma actúa, en dependencia de factores causales altamente complejos y variables, en períodos cronológicos no contemporáneos respecto a diferentes zonas territoriales.

(De Granda 1994: 60-61).

Desde el punto de vista metodológico, se trabajó con un corpus base total de 216 documentos,

\footnotetext{
${ }^{1}$ La otra propuesta, complementaria con ésta, es la que ha formulado Guitarte (1980: 120) de la división del español colonial en tres períodos: "1) uno de orígenes o formación del español americano; 2) otro de su vida como lengua de una sociedad colonial ya sólidamente establecida, y 3) por último, un período de pasaje a la época independiente, que abarcaría los decenios finales del siglo XVIII y los primeros del XIX".
} 
comprendidos entre los años de 1548 y 1798, de entre los cuales 51 corresponden al siglo XVI, 83 al siglo XVII y 82 al siglo XVIII, todos ellos de carácter original, no literarios, procedentes del Archivo de Indias y del Archivo Nacional de Santiago de Chile. Cabe destacar que la selección de los documentos reduce siempre la muestra a su mínima expresión, ya que es deseable siempre contar con autores plenamente identificados a fin de determinar la incidencia de variables demográficas, sociales, culturales u otras en el desarrollo de la evolución de nuestra lengua en Chile.

Además, en la selección del corpus se ha tratado de reunir la mayor cantidad de cartas privadas, en la medida en que esto ha sido posible, como testimonio de primera mano para el análisis, por cuanto su redacción está más libre de trabas tipologizantes y, en consecuencia, dan a conocer de mejor forma la variación social y estilística. Con todo, aun cuando se reconozca la supremacía de los textos privados sobre los oficiales, este criterio no siempre es aplicable, debido a que la documentación celosamente resguardada, atesoradora de los más invaluables y significativos manuscritos, que dan testimonio de las diversas actividades de la vida pública nacional, mal que pese, en su mayoría dan cuenta de la vida privada y, junto con ello, del modo familiar o cotidiano de la expresión, cuando la emisión o recepción de ellos podía estar a cargo de algún personaje connotado o trascendente en el quehacer de su comunidad. Tal es el caso, en el corpus analizado, de las cartas enviadas a Juan de Ugarte Urrispurro y las escritas por él, por ejemplo. Esto dificulta aún más poder lograr un continuo estilístico que represente a la sociedad de la época, pues debe recordarse que el porcentaje de alfabetismo no era muy alto, con lo cual el nivel de quienes escriben estará necesariamente sesgado en este aspecto. Sin embargo, para suplir estas posibles deficiencias se ha hecho acopio de documentos que, si bien no personales, se acerquen lo más posible a estas características, debido a su grado de informalidad, escritura apresurada en el lugar de los hechos o de seguimiento de un proceso verbal, siguiendo así lo expresado por Frago en cuanto a que:

la conveniencia de recurrir a un equitativo análisis de corpus no literarios a la hora de investigar en las diferentes facetas históricas del español se acentúa, y aun se convierte en necesidad esencial, cuando del español americano se trata, ya que el período de su configuración como habla regional diferenciada (...) es de una literatura hispanoamericana de escasa identidad (...). En cambio, disponemos de un inabarcable acervo textual del todo válido para el más exigente análisis filológico.

(Frago 1987: 70).

La única excepción que se ha hecho a esta regla la constituyen aquellas cartas dirigidas al Rey y que forman parte de la colección de textos chilenos incluidos en los Documentos para la Historia Lingüística de Hispanoamérica (DHLH).

Por otra parte, respecto a los límites geográficos que implica la denominación "Reino de Chile", conviene hacer algunos alcances. La administración de la Corona española tenía muy claramente establecida la clasificación y organización de sus territorios imperiales. Por un lado, en la Península, el Reino; allende sus mares, en América, los Virreinatos de México, Perú y, posteriormente, el de La Plata; las Gobernaciones de Tucumán o Buenos Aires; la Capitanía General de Chile; la Real Audiencia de Charcas, designaciones encontradas -en su mayoría- en la documentación archivística existente en el país. Sin embargo, quien escribe no se identifica con la caracterización oficial; es más, la primera denominación oficial de la que se hace mención en relación con estos territorios es la de reinos de la Nueva Extremadura, en documento de Luis de Cartagena (Nov 25, 1548). Respecto de esta circunstancia, Villalobos (1983: 33) señala que la denominación de "reino" era característica de estas provincias de ultramar, careciendo de una connotación definida, jurídicamente hablando, y podía designar a cualquier territorio más o menos extenso que se encontrase delimitado administrativamente, aun cuando el uso le asignó, preferentemente, esta denominación a Nueva Granada, Quito y Chile. Aunque tal expresión haya sido ficticia, se ha preferido el atenerse a ella, ya que así lo han querido nuestros autores los cuales, en la datación de sus documentos, hacen única referencia a la expresión Reino de Chile.

A su vez, en cuanto a los límites geográficos considerados pertinentes en la realización de este trabajo, cabe realizar otras precisiones. Es ampliamente conocido que la primera división realizada por la Corona de los territorios americanos fue una solución "intramuros", como recuerda Villalobos (1983: 254), ya que la geografía regional era desconocida, y así llegaron a otorgarse cuatro gobernaciones, entre 1529 y 1534, de acuerdo con los siguiente paralelos: Nueva Castilla, entre el río Santiago y el paralelo 13\%40' (Chincha), para Francisco Pizarro; Nueva Toledo, entre los paralelos $13^{\circ} 40^{\prime}$ y $25^{\circ} 31^{\prime}$ ' (Taltal), para Diego de Almagro; Nueva Andalucía, entre los paralelos 2531' y 36 $57^{\prime}$ ' (Arauco), para Pedro de Mendoza y Nueva León, entre los paralelos $36^{\circ} 57^{\prime}$ y $48^{\circ} 22^{\prime}$ ' (Isla Campana), para Simón de Alcazaba; posteriormente, en 1539, esta última fue reasignada a Francisco de Camargo, desde Arauco hasta los últimos confines del territorio. Las dos últimas son de especial interés para esta 
investigación, ya que estos límites territoriales son asumidos por Valdivia al encontrarse "vacantes" de conquistadores.

Los límites del territorio fueron fijados de facto, ya que la Corona privilegiaba las conquistas efectivas más que las cédulas otorgadas. De esta manera, Almagro sobrepasa con su expedición los límites de la zona asignada, siendo Pedro de Valdivia -teniente de gobernador de Pizarro- quien se encarga de configurar los márgenes del nuevo "reino" americano desde el valle de Copiapó (paralelo $27^{\circ}$ ) hasta las cercanías del canal de Chacao (paralelo 41\%). Los límites hacia "lo ancho", conservaban el espíritu de las primeras capitulaciones, ya que otorgaban a Chile cien leguas -unos 634 km-, lo cual dejaba dentro de la jurisdicción territorial parte de Tucumán, Cuyo y la Patagonia. Debido al distinto desarrollo histórico y lingüístico de estas regiones "allende los Andes", se considerará para este caso sólo los territorios comprendidos "aquende los Andes".

\section{FONÉTICA PENINSULAR}

En cuanto a las características fonológicas que hemos analizado en la documentación de estos tres siglos, debemos señalar que los rasgos fundamentales de la conformación dialectal de la lengua española en Chile se basan esencialmente, como se verá más adelante, en aquellos que han delimitado la variedad andaluza -tal como lo ratifica Enguita (1992) respecto de Hispanoamérica- producto del predominio demográfico de los hablantes de esta región, así como del proceso de nivelación linguiística que favorece a las modalidades más simplificadoras.

Junto con la preponderancia que el contingente andaluz tiene en el panorama social chileno desde el siglo XVI hasta finales del XVII, por supuesto también encontraremos rasgos propios de su hablar en la modalidad nacional. Y es que el testimonio de cuestión tan vital ya lo encontramos desde los inicios de nuestra hispanoamericanicidad, tal como señala Frago:

En los mismísimos inicios de la colonización española de las Indias se aprecia la huella que el dialecto andaluz va dejando en los papeles colombinos, tanto en los de carácter autógrafo como en los que el Almirante mandó copiar a sus amanuenses, independientemente, claro está, de que fueran escritos en Castilla, en la Española o en alta mar.

Efectivamente, en textos de tan insigne autoría redactados entre 1493 y 1504 se verifica la completa indistinción de -ss- y $-s$-, con registros como los de defendiese, fallasen, fuésemos, llegásemos, pasar, podiesen, tardasen, toviesen, viniesen (Doc.II); enbiase, lebase, oviese, perteneciese, pusiese, sacase (Doc. VI); mandase, pasa, posesión (Doc. VII); confomase, fuese, supiésedes (Doc. X), texto que asimismo contiene la frase "pidos ['pido os'] por merçe ['merced'] que me lo digáys", enormemente plástica en su expresión fonética; diesen, entendiese, fiziesen, fuese, oviese (Doc. XVI). [...] Es más, también se verifican casos seseosos en esta colección, con las formas Gonsáles y parese (Docs. VII, XVI), así como el trueque de $X$ por $s$ en bexa 'besa' ("a la cual bexa sus reales manos por mín": Doc. III), y el contrario en "la armada que yo truse", "porque todo está ganado y debaso su real señorío", "suplicó a Sus Altezas que le desasen poner un juez acá", "que le desasen contribuir la ochava parte", "que les ganó y tiene puestas debaso su real señorío", "de la justiçia çivil y criminal, alta y basa", "y asimismo que todo lo que trusiere de las Indias sea con su firma” (Docs. VII, XVI, XVII, XVIII).

(Frago 1994: 19).

Ya desde esta temprana época se vendrán a manifestar rasgos tan esenciales como el del seseo, mas no sólo en textos meridionales, de andaluces, extremeños del sur y canarios, sino también de peninsulares que habiendo estado en contacto con la nueva realidad lingüística americana terminaron por adoptar algunos de sus aspectos más significativos, tal como es el caso del madrileño Ginés de Toro Mazote, en el siglo XVI.

Otra característica esencial es la particular difusión que alcanza la aspiración de /f-/ latina y que [h] haya pasado a ser un alófono más de /x/ en territorio andaluz y gran parte del americano. Del primer proceso, que ha sido conocido por los demás dialectos peninsulares, podemos señalar que su particular duración y afincamiento es lo que lo caracteriza, ya que, en palabras de Frago:

A finales del siglo XV en el corpus de los repartimientos malagueños buhonero, haga, haziéndose, haça, hazera, higuera, hija, hilo alternan en los mismos folios con fanegadas, fazer, farán, fizo, figuera, y no hay en él términos que, pudiendo tener aspiración derivada de /f/ latina o de /h/árabe, no presenten $f_{\mathrm{o}} h$ : en vista de lo reciente que era la corriente por la supresión de la $f$ en la lengua escrita y del predominio de la $h$ sobre la letra anterior que este documento verifica, lo más probable es que aquí la aspiración se refleje de principio a fin.

(Frago 1993: 398). 
Del segundo, las noticias nos llevan al primer cuarto del siglo XVI, aun cuando no debe dejarse de tomar en cuenta que el fenómeno ya debería estar arraigado como para manifestarse tan expresamente en la escritura de autores con un considerable grado de erudición.

Característica del andaluz es también la pérdida de /-s/ implosiva, aun cuando se hallen testimonios esporádicos en varias regiones de la península, pero el arraigo que ya tiene a comienzos del siglo XV en la andaluza no deja lugar a dudas de que allí era parte de un complejo dialectal más estructurado, como lo demuestran la gran cantidad de casos que se han aducido en los diversos estudios que sobre éste se han realizado. Por otro lado, rasgos como el yeísmo o la neutralización de /-r, -1/ implosivas se hallan lo suficientemente atestiguados como originariamente andaluces $\mathrm{y}$, desde los textos recogidos por BoydBowman en México, testimoniados desde la etapa formativa del español americano.

Una vez revisadas estas características aportadas por el dialecto meridional andaluz y que conformaron el desarrollo histórico de la lengua española no sólo en Chile, sino por cierto en toda América, pasaremos a configurar el trazado que siguen los rasgos de este tipo en el habla de quienes se incorporaban a la realidad lingüística de las tierras indianas, ya sea por asentamiento o por origen. Para ello, comenzaremos dando cuenta de uno de los rasgos que más caracteriza a toda esta región y que la vincula directamente con el mediodía peninsular, como es el del seseo. No repetiremos aquí consideraciones teóricas sobre el mismo, sino que nos remitiremos a los testimonios documentales y a la interpretación que éstos nos merecen, dentro de los contextos histórico-lingüísticos pertinentes.

En primer lugar, refiriéndose a este fenómeno, Matus et al. declaran:

En los siglos XVI y XVII se manifiesta coexistencia de diversos sistemas de sibilantes: $50 \%$ de los autores de estos siglos son distinguidores de punto de articulación y 50\% confundidores (seseantes). El siglo XVII aparece como época de consolidación de la neutralización (seseo): entre los confundidores hay 2 de origen desconocido $(1614,1626)$, un andaluz (1664), soldado por más de 30 años en Nápoles, Milán, Cataluña y Flandes, que escribe el documento al año de llegar a Chile, y un criollo nacido en Lima (1671) y educado en Salamanca; éstos no pueden contarse en el proceso de arraigo del fenómeno. Muy significativo es también que los 4 confundidores estén representados por un criollo (muy tempranamente, 1607), un andaluz (1613), un vasco (1650) y un obispo criollo nacido en Lima (1680). Así, en 1607, escribe el criollo Fray Pedro de Salvatierra: ocaçiones, limozna; Diego de Ulloa, andaluz, en 1613: sertifico, consediese, quarenta y sinco. El vasco Bernardo de Amasa anota en 1650: jusgan, lisençia, ciento y sinquenta, haserme y el obispo criollo Fray Bernardo Carrasco y Saavedra en 1680 apunta: trançito, reconosido, diuiçion, mejoraze. El siglo XVIII aparece fehacientemente marcado con su $100 \%$ de confundidores, lo que es prueba de seseo generalizado: en 1755, Fray Manuel Rodríguez, criollo, escribe: opocission, sencible, acaesido, conciderarse.

(Matus et al. 1992).

En parte coincidimos con esta afirmación en lo relacionado con la coexistencia de los sistemas de sibilantes, ya que, como era de esperar, los peninsulares que acaban de llegar a los territorios americanos traen sus propias características dialectales; sin embargo, la extensión del mismo parece ser mucho más amplia de lo que supusimos en alguna ocasión, pues ya no se trata solamente de verificar la existencia de este fenómeno en autores criollos, de los que ya hablaremos más adelante, sino que, revisando las muestras documentales, hallamos que los autores peninsulares demuestran en la escritura informal una gran permeabilidad a las dicciones seseo-ceceosas, aun cuando, en un primer momento y sobre todo en individuos centro-norteños, pueda tratarse de un estadio preliminar de pérdida de la distinción fonológica, habida cuenta de lo ocasional de los ejemplos en textos cuya formalidad escrituraria no respondía, precisamente, a los estereotipados cánones de la Corte. Estos pudieran ser los casos de un Johan de Céspedes, quien en uno de sus textos pone çenço, ynsiertos y jusgada o el de Francisco de Gálvez, quien, en carta al Rey, desliza un pruçiçiones; ni qué decir tiene ya el caso del cultísimo matritense Ginés de Toro Mazote, el cual, aparte de ser un prolífico escribano -una vez, eso sí, dejadas sus funciones de capitán-, es quien nos proporciona la mayor muestra seseosa del siglo XVI. Si bien, con todo, la cantidad de ejemplos pudiera parecer a más de alguien escasa como para realizar cualquier afirmación en este sentido, no debemos dejar de considerar que, en primer lugar, la escritura se halla siempre mediatizada por el prurito cultural de la formación escolar, lo cual es posible observar muy claramente en autores como un Nicolás de Garnica, Luis de Cartagena, Fray Joanes de Vega, Francisco de Paredes o Fernando de Guzmán, ya que, teniendo todos ellos una lengua materna o un dialecto no distinguidor, se apegan a la ortografía tradicional, sobre todo en el caso del primero, vasco probablemente bilingüe, quien incluso parece más sujeto que ninguno a las formas medievales para evitar posibles errores en su actuación notarial. Así, en este siglo XVI, se observa que de 27 autores peninsulares -sólo hemos 
revisado documentos, para esta época, de 3 criollos- 14 de ellos presentan grafías seseosas ${ }^{2}$, es decir, un $51,8 \%$ de ellos, lo cual no deja de ser un porcentaje relativamente alto si tenemos en cuenta que 16 de ellos son de origen extremeño o castellano y que pudiera aumentar al examinar textos más informales de algunos de los meridionales y vascos que por cultismo escolar no lo manifiestan.

En todo caso, lo anterior no deja de ser un dato que llame la atención, puesto que los diversos testimonios que se han recogido hasta el momento señalan a los autores peninsulares no meridionales como conservadores de la distinción de las sibilantes, siendo los andaluces, canarios y parte de los extremeños quienes habrían contribuido, en definitiva, a la difusión del fenómeno. En este sentido, se pronuncia desde un comienzo Frago:

Sin ningún género de duda es el apartado fonético-fonológico el de mayor rendimiento en la tipificación dialectal y sociocultural del español americano en el siglo XVI. Y ello no por otra razón sino porque en los comienzos de esta centuria en España se había consumado ya el grueso de los fenómenos evolutivos constituyentes del reajuste consonántico del castellano medieval y del fonetismo meridional. De manera, pues, que a Indias pasan usuarios de las dos principales normas fonéticas existentes todavía hoy, con el considerable peso que entre las hablas meridionales tienen, y tenían también entonces, las andaluzas, tanto por cuestiones demográficas y de arraigo social de lo dialectal como por el específico carácter de algunos de sus rasgos. En América se reúnen gentes de una y otra modalidad lingüística, dándose inicio así a un largo proceso de síntesis y nivelación de los hechos diferenciales, en el cual el triunfo acabaría correspondiéndoles a ciertos modismos profundamente teñidos de andalucismo, y de ellos hay que mencionar al seseo como caso muy especial en todos los sentidos. [...] De todos modos, el análisis filológico de la documentación americana arroja información abundantísima y fidedigna como para que por su intermedio sepamos con toda seguridad que el español trasplantado a Indias se encontraba fonéticamente fragmentado. Efectivamente, en lo tocante al fenómeno seseo-ceceoso, los textos escritos por los no andaluces mantienen la distinción de $c-z$ y $s$, mientras mayoritariamente las confunden los de los andaluces [...]. Bien es verdad que la confusión grafémica no es pareja en todos los autores, sino que depende mucho de la formación intelectual de cada cual, de la disciplina escrituraria adquirida en la escuela o en el oficio curialesco, y hasta de particulares sentimientos de corrección. De toda evidencia es que estas circunstancias no han de echarse en saco roto a la hora de establecer la valoración lingüística de los deslices ortográficos cometidos por los distintos escribanos.

(Frago 994: 70-71).

Nuestra documentación del siglo XVI, sin duda alguna se hace partícipe de esta tendencia, pero también es cierto que los testimonios aducidos de los tres castellanos nuevos que presentan grafías seseosas, a la luz de la cantidad de años que han pasado desde su llegada a Chile y de su nivel cultural, nos lleva a pensar que habrían adquirido este rasgo en tierras americanas y que ya se comenzaría a manifestar en su habla por esta época y quizás mucho antes en el caso de Ginés de Toro ${ }^{3}$.

Por supuesto, si ya teníamos un significativo porcentaje de autores que en el siglo XVI presentaba grafías confundidoras, era de suponer que en el XVII esta tendencia se viera fuertemente incrementada, donde claramente ya no es posible hablar de una coexistencia de sistemas fonológicos, elevándose el índice de casos seseosos al 88,9\%, máxime considerando los testimonios de los autores peninsulares de este siglo los cuales, salvo por 3 de ellos de quienes poseemos un breve documento, tienen prácticamente por norma el dar a la pluma grafías seseosas, incluso en casos tan poco frecuentes como el del leonés Francisco de Salamanca, quien pone Costansa, conosidos, perese, Altesa y necesario o el del castellano viejo Miguel Sáez de Mena que escribe serro, alféres, paresió, balidasión, justisias, por mencionar sólo algunos ejemplos.

De hecho, la incorporación norteña a este rasgo es sumamente significativa desde el punto de vista cualitativo, pues en ella encontramos tendencias que no se habían manifestado anteriormente en

\footnotetext{
${ }^{2}$ La mayor parte de los documentos de autores meridionales que no las registran son cartas al Rey, muy cuidadas y formales, lo cual no impedirá, por supuesto, que su autor no seseara en el habla, cosa bastante probable entre vascos y andaluces occidentales. Esto nos obliga a relativizar cualquier posible cuantificación, hasta que nuestra base documental no sea lo suficientemente amplia como para permitir este tipo de extrapolaciones, pues es posible que se encontrara más de algún caso en que éste u otro fenómeno se halle en textos familiares o, al menos, más informales y espontáneos, no así en los más oficiales y retóricos.

${ }^{3}$ Brevemente, podemos decir de estos peninsulares lo siguiente: Johan de Céspedes, natural de Ciudad Real (Torralba), hijo de Juan de Céspedes y de Isabel de Poblete; pasa a Chile en 1554, siendo Factor Real y Veedor de Hacienda bajo el Gobernador D. García Hurtado de Mendoza; como tal actuó en la proclamación de Felipe II como Rey de España, en la Catedral de Santiago, el 17-IV1558. Francisco de Gálvez, natural de Madrid, hijo legítimo de Pedro Gálvez y de Francisca de Montoya, soltero; pasa a Chile nombrado Contador Real de las Provincias de Chile, por Real Cédula, en 1567. Ginés de Toro Mazote y Peñalosa, natural de Madrid, sobrino de Francisco Martínez de Peñalosa y Vergara, Conquistador del Perú y Chile; pasa al Perú en 1565 y a Chile en 1567; escribano público y de cabildo de Santiago entre 1584 y 1606; casado antes de 1577 con Elena de la Serna, nt. Santiago, hija del Cap. Andrés Hernández y de Magdalena de la Serna.
} 
castellanos viejos y aragoneses. Asimismo, no es por nada que de los 27 autores peninsulares analizados en este siglo, 24 de ellos manifiesten casos de confusión, que ya son particularmente abundantes en los textos de vascos, meridionales y canarios.

Finalmente, en el caso de los peninsulares del XVIII (14 en total) contamos con sólo dos norteños -el castellano viejo Manuel de Cabezón y el toledano Gabriel Cano de Aponte-, constituyendo el resto una muestra de extremeños, andaluces, vascos, navarros y gallegos. No obstante, encontramos que todos ellos presentan grafías seseosas, incluyendo a los ya mencionados, de los cuales se puede leer Mendosa, Vgas (7v.) Vgaz (2v.), zé 'sé', bos 'voz', euisión 'evicción' y Mendosa, en el primero, y asiéndose, execusión, jueses, justisia, necesario, presentasión, prosederá, prosediendo, siudad y sufisientes, en el segundo.

Tal vez en estos momentos cabe recordar que en la región de Tucumán, entre los siglos XVI y XVII, 9 de los 10 autores estudiados por Rojas (1985) presentan confusiones seseosas, entre los cuales se encuentran toledanos, riojanos y castellanos viejos. $\mathrm{Si}$ a esto sumamos las similares situaciones observadas por Cock (1969) en el Nuevo Reino de Granada, donde hablantes de regiones distinguidoras pasan a ser confundidores, tal vez pudiera reconocerse un proceso de criollización en la lengua de estos inmigrados ${ }^{4}$.

Por otra parte, en cuanto a los casos de aspiración de $f$ - latina y velarización de las palatales / $\check{s}$, ž/ tenemos que decir, respecto de la primera, que nuestro corpus documental está en concordancia con esa primigenia tendencia de mantener la aspiración, al menos eso se deduce del uso regular, en la mayor parte de nuestros autores, de $h$ - donde correspondía una $f$ - latina o aspiración árabe, tal como lo señala Frago, cuando dice:

El doctor Melgarejo seguramente mantenía la aspiración procedente del lat. /f-/, puesto que sin excepción pone la $h$ con tal referencia etimológica; pero en Diego de Carvajal esa pronunciación aspirada es indiscutible, porque no sólo emplea con idéntico rigor la misma letra, sino que en juiendo la intercambia con la $j$, lo cual incluso puede indicar una articulación aspirada de la velar /x/.

(Frago 1994).

A pesar de este uso sistemático, desde los primeros documentos del siglo XVI empezamos a hallar muestras de pérdida de $h$ - como representación de la aspiración, como, por ejemplo, en el caso del cordobés Luis de Cartagena quien escribe arto, el vasco Nicolás de Garnica, al poner un caso de açe, el castellano nuevo Fray Juan de Torralba al escribir un olgarían o los extremeños Juan de Villalobos açerme- y Alonso de Sotomayor -errar 'herrar'-, el matritense Ginés de Toro -achas, azuelas, erramientas, oja, orno; echura-) o el del andaluz Juan Bautista de Campos, quien pone un caso de arina.

Si contrastamos estos datos con los de la demografía peninsular de la época, podemos decir junto con Matus et al. que:

Lo anterior hace suponer, también para este fenómeno, un período de coexistencia de dos sistemas en la época multidialectal, que los datos no permiten delimitar en su término. Por ello, no parece adecuado suponer, en la "lengua de los conquistadores", un solo sistema en el que figurara necesariamente /h/ aspirada (Oroz 1966: 30). En la Crónica de Vivar (1558) ocurren numerosas formas ultracorrectas. Tal vez los castellanos nuevos la mantuvieran algún tiempo, pero debió debilitarse pronto y caer. Fontanella (1987: 24) comprueba que algunos conservaban la aspiración a fines del siglo XVI; lo mismo Rojas (1985: 55ss.)

(Matus et al. 1992).

En todo caso, no hemos considerado aquí ningún tipo de ultracorrección, pues en éstas no hay seguridad de que se trata de corregir por omisión de $h$ - $<f$ - latina o por la pérdida ya generalizada de la $h$ etimologizante, lo cual parece ser la hipótesis más sustentable, a la luz de lo que nos revelan las transcripciones de los documentos. En tanto, en el siglo XVII, llama poderosamente la atención que, de 27 autores peninsulares, sólo un tercio de ellos dé muestras gráficas de la pérdida de la aspiración, conservándose un uso sistemático de ella en los otros $2 / 3$ restantes. Digo que no deja de ser notable, pues

\footnotetext{
${ }^{4}$ Cock (1969: 101) señala: "Estos tres autores, naturales de regiones de la Península donde no se practicaba el seseo, debieron tomar el hábito en el Nuevo Reino en su estancia de cuarenta y tres años el primero y de diez años los dos últimos. Sí debía existir, entonces, como dice Alonso, un medio lingüístico americano, al que se asimilaban en muchos casos los peninsulares establecidos en América. Y uno de sus rasgos característicos era sin duda el seseo". A lo que Fontanella (1993: 56) agrega: "Las confusiones aparecen tanto en los documentos de criollos e indios como en los de los españoles procedentes de zonas no seseantes, pero de larga permanencia en América, lo que muestra que el fenómeno era característico ya de la incipiente koiné que se estaba formando en estas tierras".
} 
los testimonios suministrados por Fontanella apuntan, precisamente, en distinto sentido:

Durante el siglo XVI, la /f/ inicial había caído en Castilla la Vieja, mientras que en Castilla la Nueva y Andalucía había dado lugar a /h/, que aún se mantenía. Los documentos americanos del siglo XVI muestran que mientras algunos hablantes mantenían aún la aspiración -representada gráficamente por "f" y "h", en variación- otros ya no la pronunciaban, pues aparecen en sus documentos numerosas omisiones de todo signo gráfico.

Alvarez Nazario señala que en Puerto Rico, en la primera mitad del siglo XVI, predominan las grafías "h" que indican la realización del fonema, aunque ya aparecen algunas ausencias esporádicas; en la segunda mitad del siglo, éstas se hacen mucho más frecuentes, lo que muestra que para muchos autores ya había caído en la pronunciación. En la región del Tucumán, Elena Rojas encuentra también numerosas omisiones de "f" o " $\mathrm{h}$ " en la segunda mitad del siglo XVI, mientras que en la región bonaerense, casi el 50\% de los autores de la segunda mitad de siglo XVI presentan omisiones de cualquier signo gráfico en palabras con /f/ inicial medieval, que en el siglo XVII se extienden a la casi totalidad de los autores.

(Fontanella 1993: 59).

Sin embargo, conviene que adelantemos que la presencia de la aspiración en esta época aún podría ser factible, en parte, puesto que hasta finales del siglo XVII encabeza la migración peninsular el grupo andaluz, lo que coincide con el testimonio de un haronada 'jaronada' del andaluz Diego de Ulloa, lo que nos da un indicio tanto de la presencia de la velar fricativa sorda como de su aspiración, que coincidiría con la de $f$ - e incidiría en su posible mantenimiento.

Respecto de las velarizaciones, lo que podemos decir con seguridad para estos siglos es que no dejan de hallarse en todo momento intercambio entre las grafías $x$ y $g, j$, como en agena, bixilia, caja, granxerías, rrejistro, vaxeças (s. XVI), o en monxas, despoxada, anegidades y conegidades, mexor, trajo, hixo (s. XVII). La confirmación de la velaridad de estas grafías la hallamos, como ya habíamos adelantado, en aquella haronada 'jaronada', donde el intercambio de $h$ por $j$ no deja lugar a dudas de ello. También, teniendo en cuenta la procedencia regional de los autores, podríamos suponer que, más allá de la tradición escrituraria, los casos de coguyeron 'cogieron' del andaluz Diego de Ulloa y, con mucha menos seguridad, los de gubón, Gigón Xixón, bernejal 'bernegal' y almofer 'met. de almofrej' del canario Domingo García, también representarían una aspiración de la velar o, al menos, su relajamiento articulatorio; además, en este último autor debe tenerse en cuenta, aparte de su procedencia canaria, la gran cantidad de intercambio entre $g$ y $j$ hallados en el documento. Dejamos de lado, por otra parte, el muguer del navarro Juan de Ugarte, simplemente indicativo de la existencia de la velar fricativa /x/, ya que el territorio vasconavarro no es aspirador.

En cuanto al fenómeno de la /-s/ implosiva sabemos, a priori, que de él dicen Matus et al. lo siguiente:

Sólo ocurren escasos testimonios de ausencia de $s$ implosiva, aunque valiosos por su ocurrencia en textos del nivel propio de nuestros documentos. Así, en 1613, el andaluz Diego de Ulloa escribe: sien ombre; en 1650, el vasco Bernardo de Amasa pone: de sus $R^{S}$ conciensia y, en 1714, el castellano Joseph de Mena Chacón anota: juridizion. Si bien en los dos primeros podría tratarse de mero error gráfico, el último refleja el fenómeno en cuestión, por cuanto ocurre frecuentemente en documentación argentina. Las conclusiones de Fontanella (1987: 28s) son coincidentes para los siglos XVI y XVII, que son de documentación oficial. Rojas (1985: 78) registra en Tucumán un par de fenómenos de principios del XVII. Oroz (1966) no se refiere a este fenómeno en su caracterización del español colonial de Chile, ni él se manifiesta en la Relación de U. Suárez (1666-1749).

Esta escasa documentación del fenómeno parece indicar que ya, hacia el siglo XVII, se producía la aspiración y pérdida de la $s$ implosiva, sólo que -por el carácter del corpus- no se manifiesta. En el siglo XVIII debió arraigar poderosamente en el habla de todos los niveles sociolingüísticos, única forma de explicar el total arraigo en textos dialectales del siglo XIX (Matus 1990).

(Matus et al. 1992).

Aparte de los casos ya citados en nuestra documentación, algo menos formal de la que habíamos transcrito para los $D H L H$, la pérdida de la /-s/ implosiva se manifiesta desde los primeros textos del siglo XVI, en autores castellanos nuevos, vascos, extremeños y andaluces. Así, el castellano nuevo Johan de Céspedes escribe "la paga del qual harán a los plazos y en la forma por ellos obligado en la dicha escritura" y el madrileño Ginés de Toro "por el ánima de Costança, yndias que fue de mi seruiçio", "por las persona a quien soy en obligación", "lo que dicho es o otro cosas o cualquier parte della", "dos bara de melinje", además de un par de casos de juridición, algo más inseguros, ya que ésta era una forma bastante común en la época medieval. El vasco Martín Ruiz de Gamboa pone en uno de sus documentos "rrepunaron los más vezino del reyno"; mientras que los extremeños Juan de Villalobos y Pedro Fernández de Villarroel sacan a relucir un caso de Yrrael y otro en el que se lee "nuebas leyes ffecha en 
Toro", respectivamente. Por último, el cordobés Luis de Cartagena, quien más ejemplos proporciona, nos entrega de su pluma "anjmando a los sanos, diziéndole palabras para esforçarlos", "nuestra santa fes católica", "deposito en vos los caçiques Ilamado Tungujllanga, Ynvalgalgue y Calchapillo", "si no todos lo que le pertenecen aunque se depositen en otra personas", "o arai ("haréis') conforme a lo que las justiçias os mandaren" y el sevillano Juan Baptista de Campos nos da un "Juan López de Barriento". Una amplia muestra de casos que incluye no sólo a sujetos meridionales, sino también a centro-norteños, aunque esto no sea de extrañar pues, como habíamos señalado en el apartado respectivo, este rasgo es propio de aquella zona, desde la cual habría pasado a las regiones situadas al sur de ella por sucesivas repoblaciones. Esto coincide plenamente, eso sí, con lo señalado por Fontanella sobre la frecuencia de este fenómeno en diversas zonas americanas:

Ya en el siglo XVI existen amplios testimonios de aspiración y pérdida de /-s/ en las distintas regiones americanas. Así, Boyd-Bowman encontró omisiones en las cartas de andaluces residentes en México -tales como démole "démosle", decisey "dieciséis" y mimo "mismo"- al igual que en otras fechadas en Guatemala, Panamá, Nueva Granada, Cartagena, Tunja, Quito. Lima, Arequipa, Potosí, Chile y [Río de la] Plata. Alvarez Nazario halló omisiones esporádicas en Puerto Rico de los siglos XVI y XVII y también hemos encontrado casos en documentos de los dos primeros siglos de la región bonaerense, al igual que Elena Rojas en la del Tucumán.

(Fontanella 1993: 59).

En nuestro caso, podemos perfectamente suponer que este fenómeno estaría generalizado para el XVII, sobre todo por los datos aportados en el corpus de la época, donde podemos hallar que el sevillano Diego de Ulloa escribe "alguno lo hazían unos myedo que era grande el que se ponía", "las aziendas ellos se la llevaban y las consumían", "las ques ('que he') dicho me pareçen son las más ynportantes", "fui con solos quatro soldados", desvilitados, mientras que el gaditano Gaspar Valdés pone un preuíttero 'presbítero'. Estos casos son perfectamente normales en autores que pertenecen a regiones de la Península donde tal fenómeno estaba arraigado, sin embargo, el caso de los navarros Juan de Ugarte y Juan de Ugarte Urrispurro y el del vasco Pedro Díaz de Zuazola ${ }^{5}$-quienes, aún pudiendo ser bilingües, no poseían esta característica en su lengua materna- puede ser atribuible al medio americano, en el cual los criollos desempeñan un fundamental papel a partir del siglo XVII.

Por último, en el siglo XVI, encontramos casos de neutralización de /-r, -1/ en dos autores castellano nuevos, como lo son el matritense Ginés de Toro Mazote, quien pone "vnos galgüellos ('gargüellos') de paño pardo de la tierra" y su coterráneo Francisco de Gálvez con un "no tiene en que le poder executar la condenaçión que le bino hecha ni con que se sustentá"; mientras que el extremeño Juan de Villalobos, en una formal y cuidada carta a S.M. el Rey, escribe unos frechaços, frecharon y frecha. Y, en el XVII, hallamos en el sevillano Antonio Xuárez Bela de Priego, un caso de pérdida de /-d-/ intervocálica en la forma de "se anime y enrriquezca la tierra que la que no tiene moneda no se pué ('puede') decir que lo es”, mientras que en Diego de Ulloa se lee un aqueias 'aquellas' de claro signo yeísta.

\section{FONÉTICA CRIOLLA}

En cuanto a los autores criollos, manejamos documentos de éstos desde la primera generación, descendientes de los primeros conquistadores, como son Diego Ortiz, Andrea Morales, Francisca Ramón y Melchor Hernández. Como es de lógica suponer, el número de autores nacionales va en aumento conforme pasan los decenios y es así que, en el siglo XVII, ya contamos con 44 autores criollos y, en el XVIII, con 54 , un $62 \%$ y un $80 \%$ del total, respectivamente.

De los cuatro chilenos antes citados, en tres de ellos se presentan confusiones seseosas -la única excepción la constituye el brevísimo texto de Francisca Ramón el cual es, además, muy estereotipadocomo las de Diego Ortiz, quien escribe poseçiones, poseçión, aprehençión, "Jllustrícimo y Reberendíçimo", Pedro de la Crus Pedro de la Cruz; las confundidoras de Melchor Hernández en "Bernardino Morales de Albornos", pocessión, adquisissión, pasíficamente o las de Andrea Morales que, aun cuando también presenta un texto de brevedad similar al de Francisca Ramón, escribe un "Juan Martín Cabesas" y un paresco, aunque este último, etimológicamente, llevase $s$ en su terminación. Con

\footnotetext{
5 Juan de Ugarte escribe "reçiban de qualesquier personas sus bienes y de quien con derecho deuan y puedan qualesquier peso de oro, plata, xoyas, esclauos", "a las presente obligaçión”, crédisto (7v.), Demótenes; su primo, Juan de Ugarte Urrispurro, pone "en los guezo" y el guipuzcoano Pedro Díaz de Zuazola, "yten vn paño de cobija con sus rranda y puntas biejo", "yten tres cuchillos de belduque nuebos con otro sinco de braguetilla".
} 
mayor o menor frecuencia encontramos ejemplos de ello en otras localidades americanas estudiadas, de las cuales son representativas estas palabras de Rojas:

Encontramos un reducido número de documentos tucumanos correspondientes a los últimos años de siglo XVI y los primeros del XVII, escritos de puño y letra por criollos. Su causa se basa, seguramente, en la tardía creación de universidades en la zona, de modo que los escribanos, alcaldes y clérigos -autores de la mayoría de estos testimonios- eran casi siempre peninsulares.

Por lo tanto, se ofrecen datos sobre las características fonológicas de sólo nueve anteriores a 1640, en relación a los cuales nos sorprende el hecho de que presentan menos testimonios de seseo que los de los españoles que consideramos anteriormente. Esto podría deberse, en realidad, a cierto cuidado ortográfico de nuestros primeros antepasados instruidos; lo que no niega la posibilidad de que, no obstante, hayan sido seseantes al hablar.

Los restantes casos que citamos en esta parte se ubican en la segunda mitad del siglo XVII. Por el número de ejemplos de esta época, deducimos para entonces el fuerte arraigo del seseo completo.

(Rojas 1985: 68-69)

Ni que decir tiene, entonces, que en el siglo XVII las grafías seseosas son la regla general entre los criollos, ya que de los 44 que hemos analizado para dicha centuria, sólo en tres de ellos no se observa este tipo de casos -Jerónimo López de Agurto, Antonio Bartolomé de Neira y Juan Henríquez-, aun cuando con toda probabilidad esto se deba a la gran formalidad y, en algunos casos, extrema brevedad de los documentos que poseemos de dichos autores. En todos los demás las confusiones se presentan en abundancia, si no en un texto, sí en otro del mismo autor. Sólo señalo aquí algunos casos, tales como saserdotes, Çantiago, Uesera 'Becerra', limozna, mersed, sesión, gose, rresadas, lanseta, dies, padese, Altesa, enpesaron, sussesores, yse 'hice', rasón, cobransa, pas 'paz', firmesa, presiosa, perzona, prosedidos, malisia, dependensias, sezaré, noes 'nuez', Gómes, antesesores, besinos, administrasión, diuiçión, porsión, veses, incerto 'inserto', trese, sesina 'cecina', autorisado, solisitud, fauoreserme, cin 'sin', mereser, fuerza y gose. De los 54 autores del XVIII sólo Agustín Caballero no muestra rastros de seseo, en un informe al Gobernador de Chile y ex virrey del Perú, Ambrosio O’Higgins; los restantes no sólo los manifiestan, sino que también lo hacen en una ingente cantidad.

En cuanto a la pérdida de la /-s/ implosiva, parece ser éste un fenómeno que no sale a la luz tan fácilmente, pues en el siglo XVI sólo se halla en los documentos más extensos y sin la misma profusión que las grafías representativas del seseo, ya que Diego Ortiz pone "y no se dimjnujan nj rrediman" y un ultracorrecto susçeda y en Melchor Hernández un solo caso de juridición el que, si bien de reminiscencia medieval, también podría haberse adoptado consciente y lexicalizadamente, como parte de un proceso de disimilación eliminatoria.

Mientras, en los textos que conforman el corpus del XVIII, este rasgo se encuentra desde un comienzo y ya hasta finales de siglo, lo cual nos hace suponer que, aún existiendo en el habla, su traspaso a la escritura es menos fluido debido a la incidencia de la escolaridad ortográfica. De todas maneras se recoge una muestra lo suficientemente importante como para que merezca ser destacada, por cuanto los distintos autores consultados coinciden en señalar su escasa frecuencia, como bien así lo indican estas palabras de Alvarez Nazario ${ }^{6}$ :

Aun cuando desde el punto de vista de la escritura reviste particular dificultad la documentación antigua de sibilantes aspiradas en final de sílaba, los textos puertorriqueños con que trabajamos presentan algunas grafías esporádicas de omisión de $-s$, cuyos casos, de no obedecer a errores involuntarios de los antiguos escribanos, podrían muy bien ser representativos del citado fenómeno de pronunciación de raíces meridionales. Así en documento notarial de 1516: "quatro pieças de los dichos los dos dello mugeres y mas vna niña"; en carta del obispo Bastidas (1543): "Se anexen el Deanago ['Deanazgo'] y calongía”; en la Memoria de 1582 nos ofrece

\footnotetext{
${ }^{6}$ Por el contrario, no deja de llamar la atención, en otro sentido, las observaciones realizadas por Parodi (1995: 99) respecto de esta consonante implosiva cuando afirma: "En un caso, en el manuscrito del vasco Francisco de Garay, encuentro el plural de dia sin /s/ (26r.8). Es probable que se trate de una omisión gráfica, más que un reflejo de una pronunciación en que se perdiera la /s/ final, pues Garay era vasco, no seseante. Por otro lado, durante la primera mitad del siglo no se registran ejemplos que pudieran reflejar la pérdida de la $-s$ en posición final de palabra. Cline (1972 p.72) no documenta ningún ejemplo e indica que "limited evidence clearly indicates that the loss of final /s/ was still abnormal in the $16^{\text {th }}$ Century". No aprecio la relación entre el personaje no seseante y la pérdida de la /s/ implosiva, habida cuenta que, revisando la documentación transcrita, no creo que haya razones para considerar la grafía sigmática como posible sustitución de $z$, ya que ésta se empleó, preferentemente, en final de palabra, como consecuencia del término del trazado de la misma y, por lo demás, dentro de todo el corpus citado, se utiliza en poquísimas palabras que pudieran prestarse en algún caso para duda, casi siempre es en reemplazo de una $s$, ya sea interior o final de palabra. Por otra parte, la falta de ejemplificación de un fenómeno en textos escritos no significa, necesariamente, que éste no exista, sino que puede persistir un prurito cultural y ortográfico detrás que impide su registro gráfico o que, mejor aún, deberíamos relativizar nuestros resultados mientras ampliamos la base documental que los sustentan.
} 
dudas la frase que lee "un rrio muy caudaloço que se dice Guayané", en la cual el hidrónimo subrayado podría ser en su forma completa Guayanés, adaptación al español, con /-s/, del nombre taíno original de Guayaney, conservado con aquella misma forma en la toponimia del país; en igual memoria aparece asimismo la referencia al punto cardinal lenordeste 'lesnordeste', con omisión escrita de - $s$ - que podría responder a caída fonética de [s]. La relación de 1625 trae además una grafía dejarretado 'desjarretado', con posible pronunciación [dehar etáðo] en la que se ha perdido la sibilante implosiva ante /h/.

(Alvarez Nazario 1991: 83).

De esta manera, en el siglo XVII leemos "como conta ('consta') por clávsula de su testamento", "avnque le he acudido a él y a Juan con los nesçessario y con la obligaçión que tenía", "por virtud destas beneffiçio sean tomados e rrestituidos en el punto en que estauan antes", "en nombre de Juan Benega ('Venegas')", "dos platone ('platones')" (Mar 19, 1610), prebítero 'presbítero', "y a la seguridad y paga desta deuda ypoteca, por espezial y espresa obligaçiones, ypotecalo que conpró", "una libras de argenttería platteada" (Mar 31,1670), "e muerto dosienta y sesenta cabesas de ganado bacuno", "me aparté de sus compañía" y "siendo con pago justos y competentes".

Esta caracterización se extiende y traspasa, por supuesto, el siglo XVIII, donde incluso encontramos un nuevo texto de María Macaya en el cual ahora, en vez de darnos un caso de pérdida como el de su texto de la centuria anterior, presenta un caso de neutralización del elemento implosivo cuando escribe: "dígo que oímollo ('oímoslo') tan discorde".

Es necesario destacar, finalmente, dos rasgos lingǘsticos que de suyo siempre han sido de muy costosa aparición en los corpus documentales que no pertenecen a autores de un nivel cultural peculiarmente bajo, me refiero a los casos de neutralización de /-r, -1/ y el del yeísmo.

En el primero, hemos podido adelantar la datación de este fenómeno hasta 1663, fecha en que Pedro Vélez escribe adbitrando, ádbitros, mientras que unos pocos años más tarde Juan de Agurto alternará los apellidos Ferrel y Ferrer y Juan Gómez, ya hacia fines de siglo, colocará de su pluma un caso de mujel.

Y empezando este expurgo, nos encontramos con que el siglo XVIII no sólo nos entrega más casos de esta neutralización, sino que éstos son aún mucho más abundantes que en el XVII, contando sólo con un documento en que su autor posee un nivel sociocultural deprimido. De esta forma, a los ejemplos anteriores se unen los de mansanal y manzanal, particulal 'particular' y reculso 'recurso', ynonmísimamente 'enormísimamente', Bardibia, buerba, mir 'mil', sardrá 'saldrá', esperimental 'experimentar' e ynbialme 'enviarme', ádvitro y arcavala 'alcabala'. A esto hay que agregar las muestras de pérdida de la /-r/ implosiva en Lispergue 'Lisperguer', Getrudis 'Gertrudis', que puede ser también una simple metátesis vulgar, y qualquié 'cualquier'; junto con los casos, aun cuando de fenómeno diverso, de faboles, Lecalós 'Lecarós' y quelido de José de Lucio.

De esto podemos deducir que las neutralizaciones habrían sido comunes en el habla chilena hasta fines del XVIII, por lo menos, con lo cual su decadencia habría comenzado al estandarizarse la norma lingüística y ser considerada como variante de prestigio, con lo cual, a posteriori, este rasgo ha quedado relegado a las capas menos cultas de la población.

Y, en cuanto al yeísmo, lo primero que se debe señalar es que se trata de un fenómeno de más difícil datación que el anterior, puesto que en este caso la incidencia de la ortografía es mucho más fuerte, por el alto contraste que implica el utilizar una $y$ en vez de una II, o viceversa, para autores que tuvieran un buen nivel cultural. A pesar de ello, en la documentación del siglo XVI podemos encontrar a Juan de Dios Salazar escribiendo: "A Antonio y a los mulatos mis encomiendas, no holuidando a los collas ('coyas') que son mis hijos", en clara alusión a los indios de paz que servían en tierras de encomenderos.

Además, en el XVII, José de Orellana escribe los hipercorrectos buelles y llo 'yo', y el antes citado José de Lucio pone Ilo 'yo' (2v.) y sulla 'suya', mientras Manuel Ignacio Alvarez de Henestroza usa la latinizante expresión velellano en vez de veleyano, que es la solución antihiática de algunos autores para veliano ("senatus velianus consultus").

Por otro lado, y sin considerar aquí los casos de aspiración de /f-/ latina y de velarización, por cuanto en la documentación criolla, salvo un ejemplo de juidora, no hay indicios gráficos que pudieran hacer pensar en que las generaciones chilenas practicaran la aspiración $/ \mathrm{h} / \mathrm{de} / \mathrm{x} /$ con notable incidencia, aunque dicho fenómeno sí debió ser muy vivo en ellas, por lo que significan los datos relativos a los emigrados y la comparación entre diacronía y sincronía.

Por lo demás, es posible afirmar, a la luz de los antecedentes expuestos, que los rasgos básicos del español en Chile -seseo y aspiración de /-s/ implosiva- están presentes de manera relativamente generalizada en la lengua de los primeros criollos, haciéndose más común su utilización en todos los niveles en el siglo XVII, conforme lo muestra su mayor frecuencia de uso en los textos de dicha centuria. 
En tanto, rasgos como el yeísmo se empiezan a atestiguar sólo a fines del XVII, aun cuando no debemos dejar de considerar las condicionantes culturales que su representación escrituraria conlleva. Sin embargo, éste es un rasgo que progresa conforme llega el XVIII y, con este siglo, el mayor alejamiento de las tradicionales convenciones ortográficas, tal vez mucho más patente en documentos chilenos del siglo XIX.

Estos podrían ser considerados como los rasgos elementales, por cuanto la pérdida de la /-d-/ intervocálica, aun cuando actualmente está sumamente generalizado, no tiene mayores registros en nuestro corpus, salvo los casos citados en sus respectivos apartados -Diego Ortiz, criollo, escribe "y en las personas nombrás ('nombradas') en la cláusula arriba qontenida” y el andaluz Antonio Xuárez Bela de Priego pone "se anime y enrriquezca la tierra que la que no tiene moneda no se pué ('puede') decir que lo es"- tal vez por estar valorado negativamente en la escala sociolinguística, con lo cual no nos es posible seguir su desarrollo histórico en estas fechas, por el momento.

En todo caso, y ahora hablando en términos generales, no nos cabría más que suscribir la opinión de Frago y Franco, haciéndonos parte en lo que respecta al español de Chile, cuando señalan que:

... a mediados del siglo XVII, como límite muy extremo, el español de América estaba ya formado en sus principales rasgos definitorios, y que incluso en pleno siglo XVI hubo quienes, y seguramente no pocos, ya practicaban un español peculiar del Nuevo Mundo. En realidad, pronto se establecieron dos grandes normas, posiblemente más, la de quienes sobre una base fonética meridional, con la asunción de indigenismos y americanismos léxicos y el apego a la tradición gramatical, simplificando las cosas, claro está, se diferenciaban por su hablar de los colonizadores de otras procedencias regionales y de los emigrados que continuamente salían de España, especialmente los originarios de la mitad norte peninsular. Con el tiempo una de estas normas fue ganándole terreno a la otra hasta hacerse general, no sin llegarse a contrapartidas lingüísticas y a situaciones de equilibrio en determinadas zonas.

(Frago y Franco 2001: 25).

Parte de este proceso, en el caso de nuestro país y en lo específicamente referido al análisis diacrónico de sus aspectos fonológicos, se ha tratado de mostrar por medio de estas líneas. Aún queda mucha tarea por delante, sobre todo si pensamos en que el expurgo documental para adentrarnos en la historia de nuestra lengua, al menos en estos confines de América, recién está comenzando.

\section{OBRAS CITADAS}

Alvarez Nazario, Manuel. 1991. Historia de la lengua española en Puerto Rico. Santo Domingo: Academia Puertorriqueña de la Lengua Española.

Cock Hincapié, Olga. 1969. El seseo en el Nuevo Reino de Granada (1550-1650). Bogotá:Instituto Caro y Cuervo.

Contreras Seitz, Manuel. 2000. "Criollismo lingüístico en el español de Chile del período colonial”. Estudios Filológicos 35: 41-59.

Contreras Seitz, Manuel. 2004. El español de Chile en el período colonial. Fonética. Colección Monográficos, Programa de Estudios y Documentación en Ciencias Humanas (PEDCH). Osorno: Universidad de Los Lagos.

De Granda, Germán. 1994. Español de América, español de Africa y hablas criollas hispánicas. Cambios, contactos y contextos. Madrid: Gredos.

Enguita Utrilla, José Ma ${ }^{a}$. 1992. "Rasgos lingüísticos andaluces en las hablas de Hispanoamérica", Historia y Presente del Español de América. César Hernández (coord.), Valladolid: Junta de Castilla y León, 85-104.

Fontanella de Weinberg, Mª Beatriz. 1993. El español de América. Madrid: MAPFRE.

Frago Gracia, Juan Antonio. 1987. "Una introducción filológica a la documentación del Archivo General de Indias". Anuario de Lingüística Hispánica 3: 67-97.

1993. Historia de las hablas andaluzas. Madrid: Arco Libros.

1994. Andaluz y Español de América: Historia de un parentesco lingüístico. Sevilla: Junta de Andalucía, Consejería de Cultura y Medio Ambiente.

Frago Gracia, Juan Antonio y Mariano Franco Figueroa. 2001. El español de América. Universidad de Cádiz: Servicio de Publicaciones.

Guitarte, Guillermo.1988. "Dialecto español de América e historia en Coseriu". Energeia und Ergon. Tübingen: Gunter Narr Verlag. 487-500.

Matus, Alfredo, Soledad Dargham y José Luis Samaniego. 1992. "Notas para una historia del español en Chile". Historia y Presente del Español en América. César Hernández (coord.), Valladolid: Junta de Castilla y León. 
543-564.

Parodi, Claudia. 1995. Orígenes del español americano. México: UNAM.

Real Academia Española. 1993. Documentos para la historia lingüística de Hispanoamérica. Siglos XVI a XVIII. $\mathrm{M}^{\mathrm{a}}$ Beatriz Fontanella de Weinberg (comp.). ALFAL, Comisión de Estudio Histórico del Español de América, Anejos BRAE N ${ }^{\circ}$ LIII. Madrid: Espasa-Calpe.

Rojas, Elena. 1985. Evolución histórica del español en Tucumán entre los siglos XVI y XIX. Tucumán: Universidad Nacional de Tucumán.

Villalobos, Sergio. 1983. Historia del Pueblo Chileno. 3 tomos. Santiago: Andrés Bello. 